\title{
Language Use and Communication Artifacts in GSM Adverts in Nigeria
}

\author{
Samuel Ayodele Dada (Ado-Ekiti, Nigeria)
}

\begin{abstract}
This is a sociolinguistic study of communication and language use in GSM adverts in Nigeria. The study was conducted to identify certain sociolinguistic strategies employed in GSM adverts in Nigeria. Our findings reveal that such strategies include: code choice, ethnography, semiotics and neologisms. The study has once again revealed that language choice especially in a multilingual community like Nigeria follows certain patterns and typology based on demographic, situational and attitudinal variants controlled by socio-cultural norms of communicative appropriateness.
\end{abstract}

\section{Introduction}

Language is one of the most important and characteristic forms of human behaviour. Indeed, sociolinguists believe that 'speaking' is almost always a social act. This is because much of the variation in speech habits can be seen as related to some social phenomena. Thus, it has always had a place either in the academic or business world. Language, a type of human activity and a system interacting with personality, society, or culture plays a central role in the arts or the social/management sciences. Of a fact, language has even intruded upon scientific and technological problems so much so that the engineers and scientists of our day cannot afford to ignore its benefits to mankind.

In spite of these perceived benefits of language to mankind, an all embracing definition of it continues to elude us due to its complexity of structure and function. Yet, any useful definition must include these two. For instance, Tremholm (1995: 82) defines language as "a rule-governed system of symbols that allows the users to generate meaning and in the process, to define reality". In other words, language is made up of sound, grammar, semantics and social context.

Thus far in literature, language has been portrayed as a human phenomenon used for the purpose of communication. That is, language - whether artificial or natural - is the major means by which human being communicates. Consequently, the essence of using any language is to communication. Indeed, to Oyewo (2000: 164) "the three most important functions of language in communication are to reveal the self, to express feelings and values, and to convey meaningful message". The main thrust of this paper as evident in Oyewo's assertion on the function of language is on why a speaker needs to carefully select his words while communicating. In sum, language is hereby defined as "an arbitrary vocal system of communication used among members of a speech community" (Dada 2004: 2).

This study investigates the linguistic techniques of advertising as communication in Nigeria with particular reference to GSM advertisement. Adverts, no doubt, rely almost entirely on the use of language. Thus, the need to examine in detail, the linguistic choices and communicative strategies involved in GSM advertisements in Nigeria with a view of evolving the patterns and typology of this form of language use.

\section{Language and Communication in Nigeria}

Language is not only a means of communication but also a necessary condition for survival for human beings. Language is a major part of our daily life being the basis of social 
integration. Language, in any society is basically for communication. It has enabled humankind to express and bring to reality great ideas. In the word of Lucas (1995: 259) "indeed language is vital to thinking itself". While to Oyewo (2000: 157) communication is "the process of transmitting, receiving and acting upon message/information, thoughts, ideas, attitudes and feelings through mutually agreed understandable/determined codes/symbols". This definition contains key words like 'transmitting', 'receiving', 'acting upon' and 'codes/symbols'. These terms point to the 'source', 'receiver', 'response' and 'language' respectively. It shows that communication is a process. This process is actually used to "inform, entertain, instruct and persuade in a given communicative encounter" (Oyewo 2000: 157). These functions bring to light the very intention of the GSM adverts which is to "persuade in a communication encounter" and "to convey meaningful messages". Thus, the importance of language alongside that of communication is brought to the fore.

Furthermore, every human society, from the most primitive to the most advanced, depends on some form of communication network. As communication is the essence of using language so it will be virtually impossible for any group of people to define successfully their common and binding interest without language. Indeed, all the so-called higher activities of humans spring from the close adjustment among individuals which we call society and this adjustment, in turn, is based upon language. Every society is organized into speech communities, each comprising a group of people who interact by means of speech. Therefore to live in many communities requires familiarity with more than one, often more than two languages.

Nigeria is indeed a multilingual nation with an estimated 516 languages (Gordon, 2005), each one playing a very significant role in the community where it is in use. It is interesting to note that apart from the many indigenous languages, which are of course the mother tongues of Nigerians, non - indigenous languages such as English, French, Arabic, German and Russian also exist. English has become a second language in Nigeria, while Nigerian Pidgin English, with probably the largest number of speakers, has also emerged as a result of contact of English with the indigenous languages (Dada 2007: 87). This means that it is only logical for advertisers to use more than one language in their commercial endeavour. Salami (1999) states that in a given speech community, speakers often use different varieties of language. The varieties may be dialects of the same language, separate languages, different speech styles or register. He also stipulates the domains for code choice as topic, person (role relations) and locale / place. The choice of either Pidgin English or Standard English by an advertiser is a strategy to reach the target audience.

Contrary to popular belief, language may not mirror reality. It does not simply describe the world as it is. Instead, language helps create our sense of reality by giving meaning to events. Language is not neutral. The words used to label an event determine to a great extent the response to it. Language has a powerful influence over people and their behaviour. In advertising, the choice of language to convey specific messages with the intention of influencing people is very important. Visual content and design in advertising have a very great impact on the consumer, but it is language that helps people to identify a product and remember it. Thus, both the mass media and the advertising personnel when reporting news and when marketing have to put into consideration the emotive power of their words.

\section{$3 \quad$ GSM in Nigeria}

GSM is the acronym for Global System for Mobile Communication. It is a technology that allows service providers (Network operators) provide mobile phone services to subscribers who pay for airtime after buying a subscriber identity module (SIM) card from the network operator. In addition to basic call facilities, the operators also provide value added service (VAS) like voice mail services, text messages, news briefing, fax and data services.

GSM became a reality in Nigeria in 2001, when the federal government invited companies with technical competence in the provision of GSM services to bid for the three GSM licences that were to be auctioned. The three companies that won the bid were: Econet wireless Nigeria, Mobile Telecommunications Network (MTN) and Communication Investments Limited (CIL). The Nigerian Telecommunications Network (NITEL) also got a licence by government fiat. The official launch of GSM in Nigeria was on the $28^{\text {th }}$ of August 2001, starting with ECONET wireless which resurrected to V-mobile and to Celtel and now to Zain. 
In addition, were MTN and NITEL. The only exception was CIL which defaulted in the remittance of its licence fee. It later metamorposized to Globacom, Nigeria's second national carrier.

It is important to trace the history of GSM in Nigeria since it gives us a better understanding of this research work. The presence of GSM in Nigeria has literally changed the face of the nation, it has made communication much easier. We are light years away from waiting for dial tones on analogue NITEL lines or spending nothing less than a hundred and fifty thousand naira on multilinks or intercellular lines. In view of the aforementioned points, it is only reasonable that in order for any of the GSM networks to be seen as network of choice by the majority of Nigerians, the company has to invest in quality advertising.

\section{$4 \quad$ The Language of Advertising}

According to Bovee and Arens (1989: 13), advertisement is "a communication process, a marketing process, an economic and social process or an information process, a public relation and persuasion process depending on the point of view". Advertisement has also been defined by Daramola (1997: 145) as "any paid form of non - personal presentation and promotion of products, services, or ideas by an identifiable individual or organization".

From these definitions above, the nature of advertisement becomes evident as follows:

- $\quad$ advertisement has an identified author,

- advertisement is a non-personal communication,

- $\quad$ advertisement is paid for,

- advertisement is well planned,

- advertisement targets a specific audience,

- $\quad$ advertisement is purposeful.

Therefore, advertisement is a communicative process that informs and influences the audience. People advertise to announce the arrival in the market of a new product or service; announce a product modification; announce a new pack; announce a price change; make a special offer; expand the market to buyers; invite enquiries; test the medium of communication; educate the consumers; sustain and maintain the market; recruit personnel among others. Thus, advertisements use communicative techniques to enliven commercial activities specifically the mass consumption of goods and services.

In studying the language of advertising, the ethnography of communication has a considerable role to play. Ethnography of communication, according to Finch (2000: 222), is "the study of language in relation to the social and cultural variables which influence communication." $\mathrm{He}$ explains further that all societies have their own rules, or conventions, about how language should be used in social interaction. It covers, for example, how sentences are used to show deference, to get someone to do something, to display verbal skill and so on. Ethnography of communication is also concerned with social as well as referential meaning and with language as part of communicative conduct and social action. Again, an adequate consideration of the interpretation of advertisements cannot be done based purely on semantic interpretation without making recourse to semiotics. Semiotics as a discipline studies meaning which derives from linguistic and non-linguistic forms of communication. It examines symbols, signs and images, pictures, diagrams, etc. as communicative artifacts. Advertisements generally adopt semiotic elements as a base to effect non-verbal communication. These are mainly in the form of graphics, cinematic devices and audio effects. In print adverts, there is usually an image component which is typically a scene that provides the background for the entire advertisement with the slogan of the advertiser's choice. Furthermore, this image may or may not be a representation of the product. Thus, the need for a semiotic interpretation of such non-verbal signals in a study of advertisements.

The GSM services provided by the different networks can be said to be identical products. Since, to an average subscriber, no one superior product exists, advertising is used to create the illusion of superiority. The first rule of parity involves the Alice in Wonderland use of the words "better" and "best". In short, "better" means "best" and "best" means "equal to". Since 
the brands are identical, they must be equally good. So "best" means that the product is as good as the other superior product in its category. A good example is this MTN's advertising strategy. On coming into the market in 2001, it only had Econet to contend with, so it rolled out a slogan: "the better connection". But when other network providers came into the market it changed its slogan to: "Your best connection". This is to make the consumer feel that in connecting to MTN, he/she would be getting nothing but the best deal possible.

Advertisers often use special words or phrases called weasel words. These expressions are often misleading. A weasel word is a modifier that practically negates the claim that follows it. The expression "weasel word" is aptly coined after the egg eating habits of weasels. A weasel will suck out the inside of an egg, leaving it with an infant appearance to the causal observer. Examples of these words are: helps, works, best, good, goodness.

With the way advertisers use language to promise consumers heaven on earth, it seems brilliant writings have no place in advertising. Hence, the study hopes to provide answers to the following questions:

- What kind of language is employed in advertising?

- What do advertisers encode in their message?

Language use cannot be excluded from the factors that cause the failure of an advert to reach its target audience. Thus, the need to explore this factor into details in a study like this.

\section{$5 \quad$ Aim of study}

The research work seeks to present a content analysis of MTN, ZAIN and GLOBACOM adverts on television, radio and in the print media from the perspective of sociolinguistics. The objective of the study is to identify sociolinguistic strategies such as code choice, ethnography, semiotics and neologisms employed by advertisers to make consumers remember and require their products.

\section{Research Design and Methodology}

This research covers mainly GSM adverts on television, billboards, handbills and radio. The study examines and identifies the various sociolingustic variables adopted in GSM adverts in Nigeria within Hymes' (1972) theory of Communicative Competence. Specifically, the basis of analysis used for the study is the "ethnography of speaking" framework with the acronym 'speaking' spelt out by Hymes (1972) as follows:

Setting/scene - Location i.e circumstances in which the communication event takes place including time and place.

Participants - People that are involved in the conversation, i.e. the speaker and the hearer.

Ends - The outcome of a speech act, viz. (i) results-oriented and, or unintended, and (ii) goals-individual and, or general.

Act Sequence - The form and content of the message of text. That is, the how and what is said.

Key - Tone or manner in which a textual message is delivered.

Instrumentalities - The different channels of speech transmission like oral, written, telephone, e-mail.

Norms - Conventions of social and speech behavior which could be linguistic and nonlinguistic, universal or culture-specific.

Genre - The linguistic form employed such as poem, letter, story, etc.

The data cut across both oral and written versions of GSM adverts obtained from both the print and electronic media. In all six adverts which have been very prominent and common in the media were used. The first three adverts, one for each telecommunication company in question here, were television advertisements analyzed using the ethnography technique. The 
other three adverts were from the print media contained either in a handbill or a billboard which were analyzed from the pragmatic perspective using semiotics as the basis of analysis.

\section{$7 \quad$ Data Analysis}

The data for analysis here have been categorized under two headings, namely: Ethnography and semiotic techniques. We start the analysis with the ethnographic techniques.

\subsection{Ethnography in an MTN Television Advert: "Mama na boy" (i.e. 'Mummy, it is a baby boy')}

This was one of the T.V. adverts of the MTN when it first came to Nigeria.

The advert started by showing a man in the hospital anxiously waiting for some news; the doctor comes and tells him something; he immediately reaches for his phone and calls his mother. He announces "mama na boy" (i.e. 'mummy, it is a baby boy'). His mother jumps up in jubilation and begins to dance and so do the other members of their village.

As stated already, Dell Hymes' taxonomy for communicative events with the acronym 'speaking' is used for this analysis as follows:

Setting/Scene

Participants

Ends

Act Sequence

Key

Instrumentalities

Norms

Genre
It was set in a hospital and a village simultaneously. The setting is one that Nigerians can identify with; a son in the city and his mother in the village baking groundnuts for sustenance. The two different classes of people are both connected to the network; the scene tells us that MTN is for everybody.

The participants are the man, the doctor, the man's mother and the villagers. The doctor did not speak audibly but he/she passes across some information to the man who has been waiting anxiously. The news is obviously positive.

The discourse is aimed at telling the audience that wherever they are MTN would grant them the capacity to exchange vital information with one another.

The locutionary act performed by the man is an assertive statement "mama na boy" (i.e. 'it is a baby boy').

The mode of communication here is speech while the form of the message is informal.

The channel of communication is the phone (an MTN link).

The rules of communication followed here are as follow: The son spoke to his mother in Nigerian Pidgin English giving the impression that his mother is either an illiterate or a semi-literate. The linguistic behaviour in the advert is the use of Nigerian pidgin English between mother and son. This is their language of communication. Thus, the advert depicts a believable relationship between literate children and their semi or non-literate family members. The paralinguistic convention in this advert is the dancing that represents jubilation.

The socio-cultural or ethnographic factor embedded in this advertisement is the preference in Africa for the male child over the female child. This is evident in the mother's excessive jubilation. The Nigerian society is still very enamoured with the boy child - the very cultural undertone of the advert. Discrimination against the female gender subsists because the Nigerian cultural dynamics still nurtures and sustains it. Indeed, the advert is a reflection of the Nigerian society where the birth of a male child is more celebrated than that of the female child. Families have been separated and wives divorced because of their inability to produce a male child. Thus, "na boy" (i.e. 'it is a baby boy') is a positive message.

The advert is a dramatic dialogue. Indeed, it depicts what communication networks look like among family members in a typical African society.

Table 1: Ethnographic Analysis of MTN'S TV Advert: "Mama na boy" (i.e. 'mummy, it is a baby boy') 


\subsection{Ethnography in Celtel Television Advertisement: "discover your favorite music"}

One of Celtel's television advertisements for analysis right now is the slogan "discover your favourite music". It is about a family of three: father, mother and a son named Junior. While on their way to the village, the man asked why Junior was silent, and he replied that he was wondering how life would be in the village. Quite boring he thought. He had to console himself with these words: "I have my music to keep me company." 
Setting/Scene

Participants

Ends

Act Sequence

Key

Instrumentalities

Norms

Genre
This advertisement is set inside a car, on the way to a village. On getting to the village, the villagers played them some music to welcome them. Junior asked his father what type of music the villagers played. His father replied that it was a traditional beat. This advert carries the meaning that Celtel covers a wide area of the country including the villages. Again, another point Celtel seems to be making is that we should discover what excites us most. And that Junior's network of choice, Celtel, is the only alternative to his happiness. With the use of Celtel link, he has his music to keep him cool. The advertisement ends on this note "where ever you go, discover your favourite music".

A man, a woman, a child and the villagers.

The probable goal of this advert is to tell potential consumers that where ever they go once they are connected to Celtel, they will enjoy uninterrupted services, music is an instance here.

The illocutionary force of this utterance is that of a command. A command is made with a confident and assertive tone. Thus, the advert is produced in a manner that shows that the speaker is fully convinced about the services of the network he/she is promoting.

The mode of communication here is speech and the form of the message is informal. The message is conveyed with the intent of persuading the hearer to take action.

The information of the advert is passed to consumers through television and radio. The two common means of passing information across to millions of people in Nigeria. This form of information dissemination has been proved to be the most effective because people who do not make it a habit to read newspaper, definitely watch television or listen to radio.

The advert obeys the norms or culture of Nigeria in that the language of wider communication in Nigeria is either English or Nigerian Pidgin English. If the advert had been in any of the indigenous languages, one would have come to the conclusion that the target audience here is any of the communities using the language in Nigeria. Thus, through language use the advert cuts across various ethnic groups and binds them together via the English language option.

The advert is a dialogue because it is a form of communication among family members. The dialogue aims at informing the public about CELTEL.

Table 2: Ethnographic Analysis of Celtel's TV Advert: "Discover your favorite music"

\subsection{Ethnography in Globacom Television Advert: "Amebo" (i.e. 'a gossip')}

'Amebo' (i.e. a gossip) is one of the many television advertisements sponsored by Globacom. 'Amebo' says conspiratorially, 'I hear say glo talk say, if you load N500 credit, you go get N575 credit instanta. (Moves to another location) I hear say glo talk say, if you load N1,000 credit, you go get N1,150 credit instanta (i.e. I understand glo gives instant bonus of $\mathrm{N} 75$ for a N500 credit card and N150 for a credit card of N1000). 
Setting/Scene

Participants

Ends

Act Sequence

Key

Instrumentalities

Norms

Genre
The advert was set against a white backdrop. White suggests goodness, purity and innocence. Its elusive nature provides serenity, the essence of perfection. The advertisers chose this because the target happens to be those who seek excellence and enlightenment in all spheres of life. Similarly, purity and recognition are a constant endeavour.

The only obvious participant here is Amebo, a character in "The village headmaster" a television soap opera popular in the 1980's. The character she acted then was that of a gossip, hence the name "Amebo". She obviously is not a staff of Globacom. She is a celebrity and Globacom uses her in the advert because Nigerians like to identify with the 'famous'.

The intended goal of the advert is to persuade people who have not subscribed already to the network to do so. And for those already a part of the network, the advert aims at informing them of Globacom's new generosity, thus encouraging them to stay with the network.

The illocutionary act performed through this medium of language is that of informing and promising.

The mode of communication here is speech while the form of the message is completely informal. It depicts what informal communication looks like in a typical African setting.

The channel of communication is the television. Globacom is the youngest of the first three GSM service providers in Nigeria and under focus here but it is quick in realizing the relevance and reach of television advertising; therefore it quickly becomes an investor in this type of image building strategy.

Amebo conveys her message through the use of Nigerian Pidgin English. Pidgin in Nigeria is one of the conventions of social and speech behavior. It is a language used by non-literates, semi-literates and even literate people. Thus, it is used so that no one is left out of the conversation. In its language choice, Globacom is obviously not discriminating among the different classes of people. In that code choice in advertising is one of the variables that could easily determine whether more people patronize the network or not.

Again, observe that the advert informs Nigerians that Globacom is giving $15 \%$ free on any recharge that is made, be it N500, N1000 and so on. This is a smart strategy by Globacom since it is a fact that most Nigerians earn less than $\$ 1$ a day, hence the best way to get them interested is to make its product AFFORDABLE (IMF report).

Amebo is the only one present in the advertisement. She talks to no one in particular, but to whoever is watching the advert; she refers to viewers using the second person pronoun "You". From all intents and purposes it can be said to be a monologue and she makes her speeches through the use of rhetorical questions.

Table 3: Ethnographic Analysis of Globacom's TV Advert "Amebo"

\subsection{Semiotic features of an MTN Print Advert}

For consideration here is the handbill of MTN that shows two young adults, male and female, looking into a box that contains some sort of light. To the right of the picture is the slogan "every where you go". The scenario painted above lends itself to a variety of interpretations. The fact that the couple is smiling while looking into the box indicates that the content of it brings them joy. This advertisement definitely targets the young adults, telling them that once they purchase the product, their lives will be joyous and the world would become a beautiful place for them through the network any day and every where they go.

Another focal point in the GSM advertisements is their choice of colour. MTN uses colour 'yellow'. Yellow is truly a joyous colour. Yellow exudes warmth, inspiration and vitality. Yellow is one of the brightest colours and it suggests happiness because of its resemblance to the colour of the sun; observe that summer for people from temperate regions is the perfect 
time to take a vacation in order to have fun. Yellow signifies communication, enlightenment, sunlight and spirituality. If your favourtie colour is yellow, then it indicates that you are looking forward to the future with hope and that you are intellectually highly imaginative and idealist. You tend to have a cheerful spirit and have an expectation of greater happiness. These are probably the reasons why MTN chose the colour and in subscribing to this network, the customer is expected to be all of the above and even more; whether all this is true is left to be seen.

Stylistically associated with the ' $Y$ ' of yellow is the ' $Y$ ' of the neologism "Yello" adopted in MTN slogans. Also note that "hello" is the most usual word for greeting when you meet somebody, when you answer the telephone or when you want to attract somebody's attention. Thus, "Yello", MTN's coinage could mean "How are you?" or "Greetings from the Yellow colour telecom company" or "This is the Yellow colour telecom company enabling you to say hello to somebody" and so on. No matter what it means, Yello is an MTN coinage that is stylistically relevant to the present analysis.

\subsection{Semiotic structure in a Celtel Print Advert}

For this purpose, we shall examine one of the billboards of this communication company. The advertisement has some texts which provide information about the product and more importantly provide anchorage for the picture of some people on the billboards with the bold inscription "Be United". Next to this we have the expression "pay a flat rate to all networks on our new unity Tariff!" Next to this again, is the expression "Discover the simplest, most straightforward tariff in Nigeria! One fixed rate to every call you make. That's all calls on our network as well as all calls to other GSM network. No more complicated charges - no more surprises!" Then Celtel's usual slogan: "CELTEL - making life better, follows all these."

The billboard has the picture of four men and three women, well dressed and obviously very happy. They all represent the various ethnic groups in Nigeria. We could recognize the Igbo, the Hausa and the Yoruba ethnic groups through their apparel. They wear self - confident smiles as they appear amused by whatsoever music they are dancing. They appear to be fulfilled in their present situation.

The scene lends itself to different interpretations as follows:

(1) CELTEL is the Africa's most preferred network due to its simplicity

(2) CELTEL aims at uniting all the various ethnic groups in Nigeria

(3) CELTEL aims at uniting all networks in Nigeria by charging lower and uniform rates. Thus, this will enable subscribers to connect with everyone irrespective of the network type.

To Celtel, life is simple and the company wants to make it lively still. This is evident in the pictures on the billboard. People from the various ethnic groups in Nigeria look quite happy, meaning that life is much better when the society is united. The background colour or official colour for Celtel is RED. Red is the single most dynamic and passionate colour which symbolizes love, rage and courage. Red as a colour is always damaging attention and it has great emotional impact. Those who select red are aggressive, impulsive and they always strive for success. Their desire to experience the fullness of living leads to constant activity. Celtel does not only use words but also colour (in this case red) to persuade Nigerians to subscribe to the network instead of any other competing network of choice. Through the use of this colour, the company is requesting customers to be aggressive, impulsive and to strive for success. Red is a catchy colour and this makes it impossible for your eyes to miss it and when your mind considers it, your heart wants it.

\subsection{Semiotic Structure of Globacom print Advert}

It is not only through the linguistic medium that communication experts depict the meaning potentials of their discourse. For this exercise, we shall focus on a particular billboard of Globacom with the inscription: "Let's be friends again." In addition to this bold inscription we have the following: 
For subscribers who have not used their lines since $30^{\text {th }}$ April 2007.

N100 FREE AIR TIME

5 FREE GLO TO GLO SMS
Lowest on net call rate

Lowest on net SMS tariffs (N6)

Lowest midnight rate at $5 \mathrm{k} / \mathrm{sec}$

Lowest midnight hours: 12 midnight to $5 \mathrm{am}$

Longest off peak weekend period: Friday

10pm - Monday 6:59am

$65 / \mathrm{sec}$ IDD rate

The billboard also contains pictures of four young ladies and two young men with a green colour background which is the official colour of Globacom. Here evidently, Globacom is trying to woo its subscribers who have neglected it due to one reason or the other. Globacom tries to bring them back by giving them N100 free airtime and 5free SMS to all Glo subscribers. Hence, there goes the full interpretation of "Let's be friends again." This Globacom strategy is meant to entice former customers as well as new subscribers. The aim of the company for guaranteeing N100 free airtime and 5 free SMS to all Glo subscribers is to bind and increase the relationship between subscribers and Glo.

As noted already, the official colour of Globacom is GREEN. Green is the colour of life and procreation; it represents freshness, security, abundance and tranquility. Green creates an atmosphere that is calm and serene. These features characterize the intense power of nature. Thus, if you select green, you invariably seek stability, balance and persistence. You are a moral and affectionate individual.

Globacom accepts that it is the youngest of all the three foremost networks in question here and in order to stand a chance in the GSM market it chose the colour green because it knows all it represents. Most of all, 'green' and 'white' are Nigeria's national colour, so if they do not appeal to your sense of aesthetics, they appeal to your sense of patriotism.

\section{Discussion}

This section makes a comparative analysis of data described here. The data consist of MTN, CELTEL, and GLOBACOM advertisements on both television and in print. This comparative analysis is done in terms of the similarities and differences in their sociolinguistic strategies. Specifically, the two strategies common to them apart from the linguistic devices are ethnography and semiotic techniques. Thus, all of them have embraced the use of linguistic devices, the ethnography technique and the semiotic technique.

The linguistic devices employed by virtually every one of them include the choice of the Nigerian Pidgin English and Standard English in reaching a very large audience. The two codes, one informal and the other formal, can be regarded as Nigeria's lingua franca as far as the informal and formal domains of language use are concerned. Hence, the wisdom that informed their choice. For instance: MTN's slogan: "Every where you go". Celtel's slogan; "Making life better" and GLOBACOM's slogan "Rule your world" are all couched in simple Standard English. Thus, they all operate with slogans rendered in simple English which implies that they all want to reach as many people as possible considering the level of literacy in the country. This reason is further strengthened by their use of Nigerian Pidgin English, the non-standard variety and the non-literate option, which the literate can easily decode too. Inherent in their use of slogans/advertisement is the use of persuasive language in order to convince customers to subscribe to a particular network rather than other networks. Thus, they all portray language as a potent and persuasive communicative instrument and a sure means of social interaction in the midst of competing interests.

Another similarity among the three networks, although outside the purview of the data presented here, is that they all sponsor events and national network programmes. These events and programmes are during prime-time so that people will notice and possibly subscribe to them. 
Their differences are evident in their employment of the ethnography (i.e. relevant sociocultural variables which influence communication) and semiotic techniques (i.e. relevant verbal and non-verbal meaningful symbols that feature in print adverts). One good example is in their choice of colour. MTN in its opinion chose YELLOW because it is a catchy colour which will get people interested in its product. Its recent "Life is beautiful" slogan is meaningful mostly because of its signature colour which indicates summer, a time for fun and laughter. CELTEL's choice of colour RED is a statement that it is ready for any competition from existing GSM companies. Unlike MTN's yellow, CELTEL's red is a more daring and exciting colour and it proves to the consumer that the network is ready to take risk and most of all, it is in love with its customers since red is supposedly the colour of love.

For GLOBACOM, its choice of the colour green, is a representation of the fact that the company knows that it has potential for growth, thus, it will not be intimidated by the existing companies. GLOBACOM wishes to be seen by its customers as a fresh company that wants all its customers to feel a sense of pride in their network of choice.

Another difference that is noticeable in these companies' choice of slogans is what MTN started with viz: "The better connection" then "Your best connection" to "Every where you go" and now it is "Life is beautiful". It is obvious that this network sets out, through its adverts, to tell the public of its superiority and its availability in virtually every Nigerian town or village.

CELTEL's choice of: "It's all about you" when it was formerly V-mobile is a statement of its commitment to its customers by placing them first. And its recent slogan: "making life better" is an assertion that life will be better for the customer who subscribes to the company.

GLOBACOM's slogan: "Glo with pride" is an indication that this network is the only one that offers quality services you can be proud of and the first to provide free Multimedia Messages Service (MMS). Today, this company has become a force to reckon with and for that reason its customers should be proud of their network of choice. Its recent slogan: "Rule your world" implies that you can call anyone, either far or near without any obstruction whatsoever.

\section{Implications for Communication}

In the analyses above, we are able to discover the significance of sociolinguistics in the study of language in advertisement in Nigeria with particular reference to GSM adverts. This was done by working out the sociolinguistic and semiotic strategies employed in advertising in Nigeria. The analysis has shown that advertising functions as a significant communication instrument.

It has been said that if people cannot discriminate reasonably, advertisers would assist them in discriminating unreasonably in some easy, warm, emotional way. The study reveals that advertisers project language as an exaggerative weapon, a persuasive communicative instrument that can easily be used to coerce the unwary into their business endeavours.

The primary goal of all advertisers is to increase sales and this is only achieved when customers are aware and convinced to act positively towards the product or services. It is of no use to have an excellent product or provide excellent services but lack the tact to communicate their existence and benefits thereby winning enough customers for the products or services.

As one can see from this discussion, advertising strategies have serious implications for the theory of communication. Communication involves transmission of information from the speaker to the hearer, and effective communication requires that the interlocutors must share certain background information, if not, communication break-down may occur. As evident from one's experience, communication break-down often occurs between the speaker and the addressee in some communicative situations, because participants did not adhere to some conversational maxims. In sum, the obvious intentions of the advertisers as presented in this discussion are:

- $\quad$ To market their products by making them inviting and competitive;

- $\quad$ To persuade the listeners to purchase the products with the sole purpose of making huge sales and profit; 
- $\quad$ To make the existence of the product known to the listener and

- $\quad$ To create preference in the hearer's mind for a particular telecom network.

Based on the analysis above, it can be said that the Nigerian telecommunication Companies say a lot more about their products and services in adverts than the actual quality of the services they render. Thus, the flexibility of the message that can be conveyed by any single sentence they employ for use. All Nigerians connected to the GSM networks can give clear testimonies with respect to the kind of services they receive. No doubt, all GSM users in Nigeria will conclude that all GSM networks in Nigeria offer lack-luster services. Their services fall short of the standard they so often portray in their adverts. Thus, their adverts promise so much while their services offer very little. In the final analysis, it is their advertisements that sell their products and not the quality of their services. No wonder a company like the MTN churns out adverts almost bi-monthly.

In conclusion, the language of advertisement in Nigeria which is solely that of persuasion is evidently more complex than it may appear or sound. Again, advertisement language also has implications for second language learning. For instance, subscribers should see beyond the surface meanings of these slogans. After all, an adequate knowledge of a language goes beyond grammatical competence to include pragmatic competence. Thus, the teaching of a second language should not be limited to the study of grammar, vocabulary and the phonological patterns of this language alone. It should also include aspects of the culture of the language in question. This will be of immense benefit to such learners in matters of communicating and even comprehending appropriately in that language.

\section{References}

Bovee, Courtland L./Arens, William F. (1989): Contemporary Advertising. Illinois.

Dada, Samuel A. (2004): The Principle of Effective Public Speaking. Ibadan.

Dada, Samuel A. (2007): "Language Contact and Language Conflict: The case of YorubaEnglish bilinguals". Kansas Working Papers in Linguistics 29: 85-113.

Daramola, Ifedayo (1997): Mass Communication. Theory and Practice. Akure.

Finch, Geoffrey (2000): Linguistic Terms and Concepts. New York.

Gordon, Raymond G. (ed.) (2005): Ethnologue. Languages of the world. $15^{\text {th }}$ ed. Dallas.

Hymes, Dell (1972): "On Communication Competence". In: Pride, John B./Holmes, Janet (eds.): Sociolinguistics. London: 269-293.

Lucas, Stephen E. (1995): The Art of Public Speaking. $5^{\text {th }}$ ed. Boston.

Oyewo, Yinka (2000): "Human Communication. An Introduction." In: Babajide, Adeyemi O. (ed.): Studies in English Language. Ibadan: 149-167.

Trenholm, Sarah (1995): Thinking Through Communication. An Introductoin to the study of Human Communication. Boston. 